\title{
A literatura em provas e exames
}

\section{La littérature dans les épreuves et les examens}

https://doi.org/10.34112/2317-0972a2016v34n67p83-103

\section{Lívia Suassuna ${ }^{1}$}

Rafael Alexandre Bezerra ${ }^{2}$

Resumo: Pretendeu-se, com este trabalho, verificar como se dá a abordagem da literatura em provas e exames vestibulares. Especificamente, investigamos como foi tratada a literatura na prova do Exame Nacional do Ensino Médio (ENEM) - edição 2012, estabelecendo correlações com a prova de literatura do vestibular 2012-2013 da UFPE. Analisamos os dois instrumentos à luz de pressupostos teóricos sustentados por autores como Cosson (2009), Bordini e Aguiar (1983), Paulino (2005) e Soares (2004). Tentando verificar se as provas estavam em consonância com o princípio teórico-metodológico de formar leitores proficientes de textos literários, realizamos uma pesquisa documental, descritiva e interpretativa. Concluímos que a prova do ENEM representa um avanço no tratamento do texto literário, se comparada a exames tradicionais, como o da UFPE. Porém, ainda há o que melhorar na forma como a aprendizagem da literatura é avaliada tanto numa prova quanto noutra, se quisermos, de fato, formar leitores proficientes de textos literários.

PALAVRAS-ChAVE: Avaliação; provas e exames; vestibular; ENEM; literatura.

RÉSUMÉ: L’objectif de ce travail a été de vérifier comment se fait l'approche de la littérature dans les épreuves et les examens « vestibulares » (épreuves d'accès aux universités

1. Universidade Federal de Pernambuco, Recife, PE, Brasil.

2. Universidade Federal de Pernambuco, Recife, PE, Brasil. 
brésiliennes). Plus précisément, on a recherché comment la littérature a été traitée au contexte de l'ENEM (Examen National au niveau du lycée) édition 2012, en établissant des corrélations avec l'épreuve de littérature du « vestibular » 2012 / 2013 de l'UFPE. On a analysé les deux instruments à la lumière des hypothèses théoriques soutenues par des auteurs tels que Cosson (2009), Bordini et Aguiar (1983), Paulino (2005) et Soares (2004). Pour tenter de déterminer si les examens étaient compatibles avec le principe théorique et méthodologique de former des lecteurs compétents de textes littéraires, on a réalisé une recherche documentaire, descriptive et interprétative. On a conclu que l'examen ENEM représente une avancée dans le traitement du texte littéraire par rapport aux tests traditionnels comme celui de l'UFPE. Cependant, il y a encore de place à l'amélioration de la façon dont l'apprentissage de la littérature est évaluée dans les deux cas si on veut, en fait, former des lecteurs compétents de textes littéraires.

MOTS-CLÉS: évaluation; tests et examens; vestibular; ENEM; littérature.

\section{INTRODUÇÃO}

Neste estudo defendemos que o ensino de literatura deve consistir num "trabalho voltado para a interação do aluno com o texto, no qual a seleção de obras que dialoguem com o horizonte de expectativas do leitor e a análise literária dessas obras permitam ao educando construir sentidos para o texto a partir de suas vivências" (RAMOS e ZANOLLA, 2009, p. 65). As autoras tecem uma crítica ao ensino tradicional de cunho historicista, marcado pela fragmentação e por informações superficiais sobre a literatura, em prejuízo da fruição de textos e de sua compreensão/interpretação. Acrescentam que o texto literário é um fenômeno de linguagem e ao mesmo tempo carrega uma visão de mundo e de humanidade, o que justificaria a presença da literatura na escola.

Nesse contexto, quisemos investigar o tratamento dado à literatura nos exames de acesso ao Ensino Superior, porque a literatura se constitui como disciplina autônoma no Ensino Médio (EM), e professores e alunos se remetem a essas provas em seus discursos - seja por tomá-las como indicadores do que é preciso ensinar, seja por entender que o sucesso nos exames é garantia da qualidade do ensino. Com efeito, exames vestibulares, em larga medida, interferem na dinâmica da escola, do currículo e da sala de aula, como atesta Abaurre (1995).

De outra parte, os anos 1990 se caracterizaram pelo traçado de políticas educacionais específicas, face à globalização, ao reordenamento do capitalismo e à divisão 
internacional do trabalho, que passaram a exigir reformas que adequassem o ensino a essa nova realidade, bem como a implantação de sistemáticas de avaliação de rede escolar. Assim, instituiu-se uma ampla reforma no Ensino Médio no Brasil, traduzida, principalmente, num novo desenho curricular e na criação do Exame Nacional do Ensino Médio (ENEM). Buscava-se, assim, enfrentar dois grandes problemas do segmento: (a) o elitismo, revelado no baixo índice de matrículas (próximo de 50\% da população-alvo e longe da universalização prevista em lei); (b) o histórico caráter dual da escola média brasileira, que atendia às camadas privilegiadas da sociedade na sua versão propedêutica e vinha reservando às camadas trabalhadoras uma formação reduzida à profissionalização precoce (CURY, 1998). ${ }^{3}$

A Lei de Diretrizes e Bases da Educação Nacional - LDB (Lei no 9394/96 BRASIL, 1996), em seu Art. 35, estabelece que o EM, entendido como etapa final da educação básica, tem como finalidades: o aprimoramento do educando como ser humano, sua formação ética, o desenvolvimento de sua autonomia intelectual e de seu pensamento crítico, a preparação para o mundo do trabalho e o desenvolvimento de competências para continuar o aprendizado.

Quanto ao traçado do currículo para o EM, em consonância com a LDB, foram instituídas as Diretrizes Curriculares Nacionais para o Ensino Médio - DCNEM (BRASIL, 2012a). No Art. $5^{\circ}$ desse documento, estão indicadas as bases do EM em todas as suas formas de oferta e organização, entre elas: formação integral do estudante; trabalho e pesquisa como princípios educativos; indissociabilidade entre educação e prática social, considerando-se a historicidade dos conhecimentos e dos sujeitos do processo educativo, bem como entre teoria e prática no ensino-aprendizagem; integração de conhecimentos gerais e técnico-profissionais, realizada na perspectiva da interdisciplinaridade e da contextualização; reconhecimento e aceitação da diversidade e da realidade concreta dos sujeitos do processo educativo, das formas de produção, dos processos de trabalho e das culturas a eles subjacentes; integração entre educação e as dimensões do trabalho, da ciência, da tecnologia e da cultura. As DCNEM propõem ainda, com o objetivo de superar o modelo

3. Destaque-se que essa tendência continua na conjuntura atual: o Governo Federal propôs, no segundo semestre de 2016, através da Medida Provisória n. 746, mais uma reforma do Ensino Médio. No Art. 36 da referida medida, determina-se que "o currículo do EM será composto pela Base Nacional Comum Curricular e por itinerários formativos específicos, a serem definidos pelos sistemas de ensino, com ênfase nas seguintes áreas de conhecimento ou de atuação profissional: I - linguagens; II - matemática; III - ciências da natureza; IV - ciências humanas; e V - formação técnica e profissional.” (BRASIL. Medida provisória n. 746, de 22 de setembro de 2016). 
curricular do tipo coleção, o agrupamento dos saberes e conhecimentos em quatro grandes áreas: Linguagens, Matemática, Ciências da Natureza, Ciências Humanas. ${ }^{4}$

Com relação ao ENEM, este já estava previsto no Art. 21 das DCNEM, no qual se afirma que o exame deve, progressivamente, compor o Sistema Nacional de Avaliação da Educação Básica, assumindo três funções principais: (1) avaliação sistêmica, com o objetivo de subsidiar as políticas públicas para a educação básica; (2) avaliação certificadora, que permite aos que estão fora da escola aferir seus conhecimentos construídos no processo de escolarização e os conhecimentos tácitos adquiridos ao longo da vida; (3) avaliação classificatória, que contribui para o acesso democrático à educação superior. No ano de sua criação (2008), o ENEM objetivava, de modo mais determinante, funcionar como ferramenta voluntária de autoavaliação para alunos concluintes do Ensino Médio. Em 2009, as funções são ampliadas e passam a ser: (I) autoavaliação; (II) seleção para o mundo do trabalho; (III) seleção para continuidade nos estudos; (IV) meio de participação em programas governamentais; (V) certificação para jovens e adultos no nível de conclusão do ensino médio; avaliação de (VI) escolas e (VII) alunos (BRASIL, 2002; MARCELINO e RECENA, 2012).

Segundo a Matriz de Referência do ENEM (BRASIL, 2012b), para a realização das provas do exame, devem ser considerados, em todas as áreas de conhecimento, cinco grandes eixos cognitivos: (1) dominar linguagens - DL; (2) compreender fenômenos - CF; (3) enfrentar situações-problema - SP; (4) construir argumentação - CA; (5) elaborar propostas - EP. Na especificação das áreas, foram determinadas grandes competências, desdobradas em habilidades, sendo estas mais diretamente relacionadas ao saber-fazer.

As provas do ENEM, aplicadas anualmente, vêm trazendo consigo tensões e polêmicas. Os que advogam a pertinência do exame apresentam os seguintes argumentos: o modo de formulação das provas e questões aponta para uma abordagem sistêmica, contextualizada e interdisciplinar do conhecimento; as competências e habilidades estabelecidas para o exame dariam maior funcionalidade aos conteúdos trabalhados; o exame teria o poder de influenciar positivamente a sala de aula, induzindo transformações curriculares e metodológicas significativas (PINTO, LETICHEVSKY \& GOMES, 2003).

Já outros estudiosos identificam no ENEM alguns problemas conceituais (mais do que operacionais), dos quais destacamos: (a) situado no contexto das reformas

4. Essas DCNEM atualizam a primeira versão, lançada em 1998. 
educacionais dos anos 1990, o exame seria mais uma forma de ataque aos espaços públicos, por adotar a lógica competitiva e meritocrática; (b) a avaliação do rendimento acadêmico individual do aluno não é suficiente para aquilatar a qualidade do ensino médio ofertado no país; seria indispensável, para isso, incluir no processo avaliativo o conjunto dos atores envolvidos; (c) provas e exames de larga escala tendem a aumentar o controle do Estado sobre escolas, alunos e professores, sem necessariamente garantir uma reflexão coletiva sobre processos e resultados; (d) ainda que os resultados do exame possam ser utilizados para transformar e qualificar a educação, a regulação do sistema seria empreendida a posteriori, comprometendo o caráter emancipatório e preditivo da avaliação; (e) exames de larga escala tendem a enrijecer e unificar os currículos, desvalorizando práticas culturais locais e gerando um movimento de busca acrítica por bons resultados (SANTOS, 2011; LOPES; LÓPEZ, 2010; PEREIRA; SOUZA, 2001; SOUSA, 2003; KRAWCZYK, 2003).

No meio das polêmicas, várias universidades brasileiras passaram, como previsto nos documentos que regulamentam e ordenam o ENEM, a adotá-lo como parte de seus exames vestibulares, como é o caso da UFPE, medida que se articula com outras formas de flexibilização dos mecanismos seletivos ao ensino superior.

Alguns estudos específicos sobre o ENEM apontaram aspectos interessantes da formulação das provas. Mildner e Silva (2002) analisaram questões da área de língua e literatura, tomando como ponto de partida o princípio de que verificação e avaliação são processos distintos. Os autores demonstraram que é sempre importante investigar a validade de conteúdo das questões constitutivas do teste. Por sua vez, Cortelazzo (2003) e Santos (2011) realizaram estudos comparativos entre o ENEM e o vestibular convencional, tendo constatado que o primeiro enfatiza competências, enquanto o segundo é mais centrado em conteúdos. Por fim, destacamos o trabalho de Lopes e López (2010), que defendem a importância de questionar os instrumentos utilizados em sistemas de avaliação de larga escala e não apenas os seus resultados.

É dentro desse contexto que inserimos nossa pesquisa. Acreditamos, em função de serem modificações recentes, que ainda há muito a estudar, no sentido de enfrentar os desafios próprios dessa etapa da educação básica, os quais vão desde o fortalecimento da dimensão formativa do EM em relação com as funções propedêutica e profissionalizante (CURY, 1998), passando pelo propósito final desse segmento de ensino, que é propiciar aos egressos o domínio do conhecimento de forma articulada com a realidade, na perspectiva da emancipação, da solidariedade 
e da construção coletiva de uma nova ordem social (ZANCHET, 2003) e visando ao fortalecimento da escola como instituição cultural (KRAWCZYK, 2003).

\section{Metodologia}

Realizamos uma pesquisa documental descritiva e interpretativa. Nosso corpus foi constituído pela prova de Linguagens, Códigos e suas Tecnologias (LCT) do ENEM 2012. Conforme o objetivo proposto, elegemos, como critérios de análise: (a) a caracterização do exame no âmbito de uma política nacional para o Ensino Médio, conforme seus fundamentos teórico-metodológicos, matriz de elaboração e documentos normatizadores; (b) as aproximações e distanciamentos entre a prova do ENEM e a prova de literatura do vestibular da UFPE 2012-2013 e (c) as convergências dessas provas com o objetivo geral proposto para o ensino de literatura na atualidade, que é $o$ de formar leitores de obras literárias enquanto exemplares de linguagem e de cultura.

\section{Discussão DOS RESUlTAdos}

Critério 1 - CaracterizaÇão da prova da Área de Linguagens, Códigos e suas Tecnologias do ENEM 2012

Em consonância com os documentos norteadores, o ENEM propõe um tipo de avaliação que priorize a autonomia do indivíduo, ressaltando aspectos cognitivos. Em contraposição a um tipo de avaliação tradicional (que em larga medida exige a memorização de conteúdos), os elaboradores do teste procuram, através das questões, ativar competências e habilidades mais amplas, que possibilitem uma melhor contextualização e uma maior aplicabilidade do conhecimento. Assim, na Fundamentação Teórico-metodológica do exame pode-se ler que as estruturas mentais se desenvolvem e são fortalecidas em todas as dimensões da vida, pela quantidade e qualidade das relações que estabelecemos com o mundo físico e social; o ENEM focaliza, especificamente as competências e habilidade básicas desenvolvidas, transformadas e fortalecidas com a mediação da escola. Em vista disso, o exame apresenta um tipo de avaliação que prioriza a interdisciplinaridade, a contextualização e a transdisciplinaridade, tudo isso, através da criação de situações-problema, que "propõem uma tarefa para a qual o sujeito deve mobilizar seus recursos ou esquemas e tomar decisões.” (BRASIL, 2005, p. 31 ). 
Ainda segundo o documento, essas situações-problema definem-se por questões em que é posto um problema para cuja solução o indivíduo lê, interpreta, analisa, compara, enfim, põe em prática várias competências transversais. Como parâmetro para a elaboração e o julgamento da pertinência das questões, o documento traz alguns indicadores em forma de pergunta:

O enunciado cria um contexto ou circunstância que dá ao item autonomia, no sentido de ser um bom recorte ou situação-problema? A tarefa a ser realizada (especificada, principalmente, nas competências transversais que definem o que se espera do trabalho proposto) está bem caracterizada e torna (a tarefa) possível de ser realizada nos limites (espaciais e temporais)? As alternativas estão bem formuladas e criam obstáculos [a serem ultrapassados], que convidam à reflexão do aluno e expressam diferentes graus de articulação entre o enunciado e a alternativa que melhor define a resolução do problema? É o conjunto do item que regula e dá direção ao trabalho? (BRASIL, 2005, p. 30-31).

Ou seja, na Fundamentação Teórico-metodológica do ENEM, notamos uma preocupação de realizar uma avaliação coerente com os princípios da autonomia e das competências transversais.

Ainda em relação à formulação, as questões do ENEM são do tipo múltipla escolha; em cada uma delas são propostas cinco alternativas, sendo apenas uma a correta; as outras podem apresentar apenas uma relação contingencial com o enunciado (por exemplo: mesmo apresentando alguma informação verdadeira, a assertiva não responde de modo suficiente a questão). Destaque-se também que, na formulação dos itens, toma-se cuidado para não haver qualquer tipo de "pegadinha" (artifício frequente em exames que requerem apenas a memorização). Além disso, cada questão deve compor um sistema ao mesmo tempo fechado (como um ciclo) e aberto. Fechado, pois seguirá um percurso: 1) alteração - cria-se uma situação; 2) perturbação - a questão traz uma "novidade"; 3) regulação - o indivíduo, após a perturbação, recuperará o equilíbrio rompido pela pergunta; e, por fim, 4) tomada de decisão - o indivíduo escolhe a solução para o problema. Eaberto, porque deve propor uma reflexão que transcenda a própria prova.

Outro aspecto a destacar é que o instrumento é formulado tendo em vista os cinco eixos cognitivos citados acima, devendo todos eles ser observados nas grandes áreas de conhecimento. Neste caso, interessa-nos em particular a de LCT, pois é nela que está inserido o trabalho com a literatura. No interior dessa área, segundo a Fundamentação Teórico-metodológica, está a leitura, considerada uma 
arquicompetência: "sem o desenvolvimento pleno da atividade leitora, todas as competências e habilidades avaliáveis teriam suas possibilidades reduzidas ou interrompidas" (BRASIL, 2005, p. 59). No texto da fundamentação, ainda se lê:

O exame propõe-se a avaliar e analisar a própria operação de ler, seus modos e tipos que ultrapassam os limites da decifração linguística e adentram em um campo semiótico amplo, responsabilizando todos os envolvidos na produção da prova com essa avaliação. (BRASIL, 2005, p. 59).

Como se pode observar, é dada grande importância à competência da leitura, pois se considera que é através dela que se pode desenvolver outras como interpretar, analisar, julgar (que são as chamadas competências transversais): "a leitura resume no ENEM os pressupostos da área Linguagens e Códigos” (BRASIL, 2005, p. 59).

Esses pressupostos ficam mais claros quando observamos a matriz de referência do teste. Nela, são propostas para a área de LCT 9 competências e 30 habilidades, que devem ser contempladas na elaboração. Como nosso objeto de estudo é o tratamento conferido à literatura no âmbito da prova, destacaremos, na análise das questões, as competências e habilidades que com ela tenham relação.

Ao todo, a prova de LCT tem 45 questões, das quais 5 são referentes a uma língua estrangeira (inglês ou espanhol). As 40 restantes tratam da língua portuguesa. Dentre estas, 20 contemplam algum aspecto da literatura, ou seja, trazem alguma situação que envolve texto literário ou movimento artístico-literário. Aparentemente se reconhece no exame a importância do trabalho com a literatura.

Observamos que a prova contém uma grande diversidade de gêneros textuais, distribuídos entre literários e não literários. Dentre os primeiros, notamos a presença de poemas, contos, crônicas e fragmentos de romances. Já entre os não literários, predominaram textos informativos e argumentativos. Além da linguagem verbal, encontramos também a não verbal - tirinhas, pinturas e fotografias. Isso nos mostra que a prova coincide com a matriz de referência, na qual é estabelecido que se explorem diferentes opiniões, manifestadas em textos de diferentes gêneros (competência de área 7). Ademais, essa multiplicidade de gêneros textuais reforça o trabalho com os eixos cognitivos, principalmente dominar linguagens e compreender fenômenos.

As competências e habilidades preconizadas pela matriz de referência para a área de LCT são contempladas na grande maioria das questões, em geral de forma articulada num mesmo item. Eis alguns exemplos: 


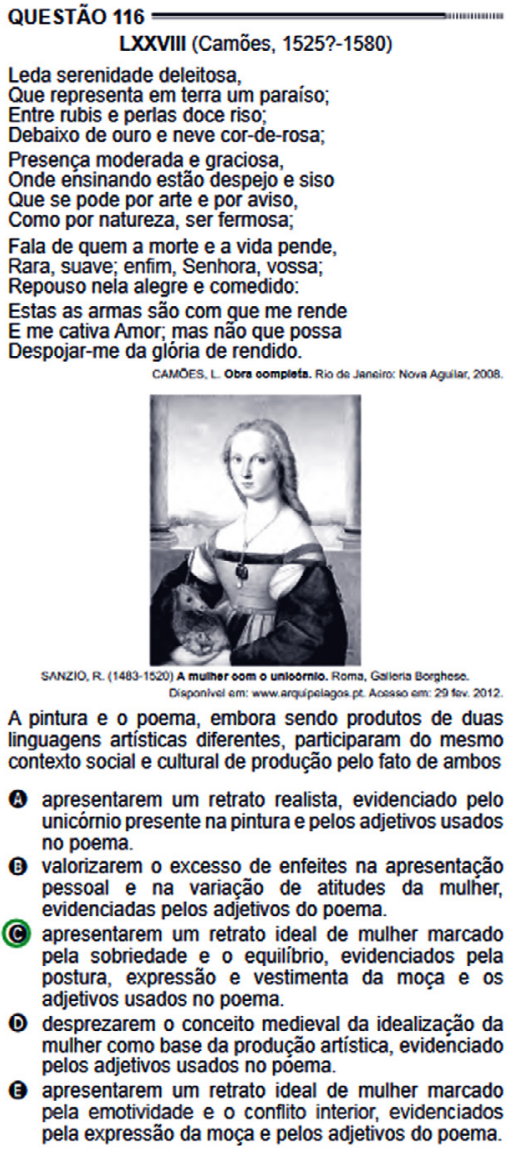

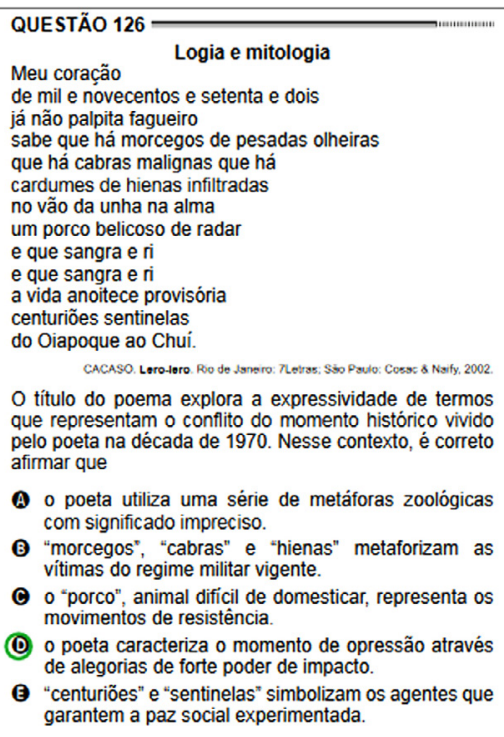

Figuras o1 e 02: Questões do Caderno 7 do ENEM 2012 - Prova Azul Fonte: INEP - Provas e Gabaritos

Na questão 116, tenta-se trabalhar com a relação contextual entre um poema (linguagem verbal) e uma pintura (linguagem não verbal). Com o intuito de fazer o candidato identificar elementos que contribuam para o desenvolvimento temático das obras apresentadas, a questão contempla habilidades como: H18 (identificar elementos que concorrem para a progressão temática) e $\mathrm{H}_{23}$ (inferir quais são os objetivos do produtor do texto).

A questão 126, por sua vez, traz um poema intitulado "Logia e mitologia", de Cacaso, que trata do contexto político da década de 1970, quando, no Brasil, 
vivíamos a ditadura militar. Na questão, faz-se uma abordagem dos recursos literários utilizados pelo autor (metáfora, alegoria, símbolos), tendo em vista a relação entre o poema e o momento histórico. Assim, a questão levaria o candidato a desenvolver habilidades como: H12 (reconhecer a possível função social do texto literário), $\mathrm{H}_{15}$ (estabelecer relações entre o texto e o momento histórico de sua produção), H18 (identificar elementos que concorrem para a progressão temática do texto) e $\mathrm{H}_{23}$ (inferir os objetivos do produtor do texto).

Além dessas duas questões, outras contemplam as mesmas ou diferentes habilidades. Por isso, num primeiro momento, podemos dizer que o exame mostra-se coerente com o que é proposto em sua fundamentação teórico-metodológica e sua matriz de referência, pois, indo de encontro a um modo de avaliação tradicional, leva em conta a intertextualidade, a contextualização, a relação entre o texto e o momento de produção, a diversidade de gêneros textuais. Enfim, a prova do ENEM é uma forma de avaliação que permite uma maior reflexão acerca dos conteúdos, se comparada a um exame tradicional.

Critério 2 - AproximaÇões e distanciamentos entre a prova do ENEM E A PROVA DO VESTIBULAR DA UFPE

Analisaremos agora a prova do ENEM 2012, estabelecendo correlações entre ela e a prova do vestibular 2012-2013 da UFPE.

As 20 questões do ENEM que trazem algum texto literário ou algo referente à literatura podem ser assim categorizadas: (1) o texto literário é usado apenas como pretexto para outros fins que não a leitura literária propriamente dita; (2) solicita-se apenas a interpretação do texto; (3) solicitam-se informações pontuais acerca de autores, obras e características de estéticas literárias; (4) realiza-se um trabalho mais significativo com o texto literário.

Observamos que predominam nessa prova itens que requerem a interpretação do texto. Das 20 questões que trazem algum aspecto referente à literatura, em 11 prioriza-se a competência da leitura de forma geral, sem que seja preciso atentar para as especificidades do texto literário. Cremos que um dos motivos para que isso aconteça é o fato de a prova integrar uma grande área de conhecimento (no caso, LCT), no âmbito da qual ganham grande importância as competências transversais (ler, interpretar, analisar etc.). Isso vai de encontro ao que diz Soares (2004, p. 1), que confronta a leitura literária com outros tipos de leitura: 
Ler, verbo transitivo, é um processo complexo e multifacetado: depende da natureza, do tipo, do gênero daquilo que se lê, e depende do objetivo que se tem ao ler. Não se lê um editorial de jornal da mesma maneira e com os mesmos objetivos com que se lê a crônica de Verissimo no mesmo jornal; não se lê um poema de Drummond da mesma maneira e com os mesmos objetivos com que se lê a entrevista do político; não se lê um manual de instalação de um aparelho de som da mesma forma e com os mesmos objetivos com que se lê o último livro de Saramago.

Entre as 9 questões restantes que integram o grupo de 20 descrito acima, 4 se enquadram na primeira categoria, outras 4 na terceira categoria e temos apenas 1 como exemplo da última categoria. Todavia, encontramos casos em que a questão, mesmo que não priorize a especificidade do texto literário, pode requerer alguma reflexão sobre o papel das figuras de linguagem (metáfora e ironia, por exemplo) para a constituição do sentido do texto. Vejamos:

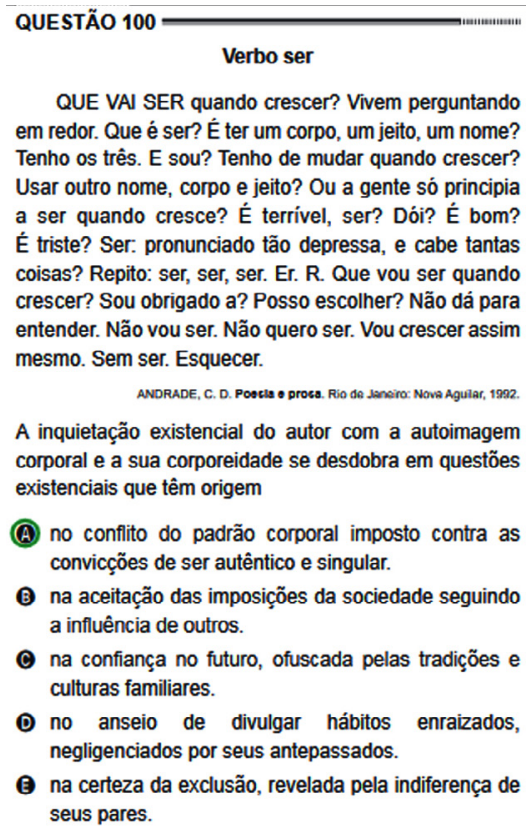

Verbo ser

QUE VAI SER quando crescer? Vivem perguntando em redor. Que é ser? É ter um corpo, um jeito, um nome? Tenho os três. E sou? Tenho de mudar quando crescer? Usar outro nome, corpo e jeito? Ou a gente só principia a ser quando cresce? É terrível, ser? Dói? É bom? É triste? Ser: pronunciado tão depressa, e cabe tantas coisas? Repito: ser, ser, ser. Er. R. Que vou ser quando crescer? Sou obrigado a? Posso escolher? Não dá para entender. Não vou ser. Não quero ser. Vou crescer assim mesmo. Sem ser. Esquecer.

ANDRADE, C. D. Poocis o prose. Rio de teneroro Nova Aguiar, 1992.

A inquietação existencial do autor com a autoimagem corporal e a sua corporeidade se desdobra em questões existenciais que têm origem

(A) no conflito do padrão corporal imposto contra as convicçōes de ser autêntico e singular.

B na aceitação das imposições da sociedade seguindo a influência de outros.

C na confiança no futuro, ofuscada pelas tradições e culturas familiares.

(1) no anseio de divulgar hábitos enraizados, negligenciados por seus antepassados.

( $)$ na certeza da exclusão, revelada pela indiferença de seus pares.

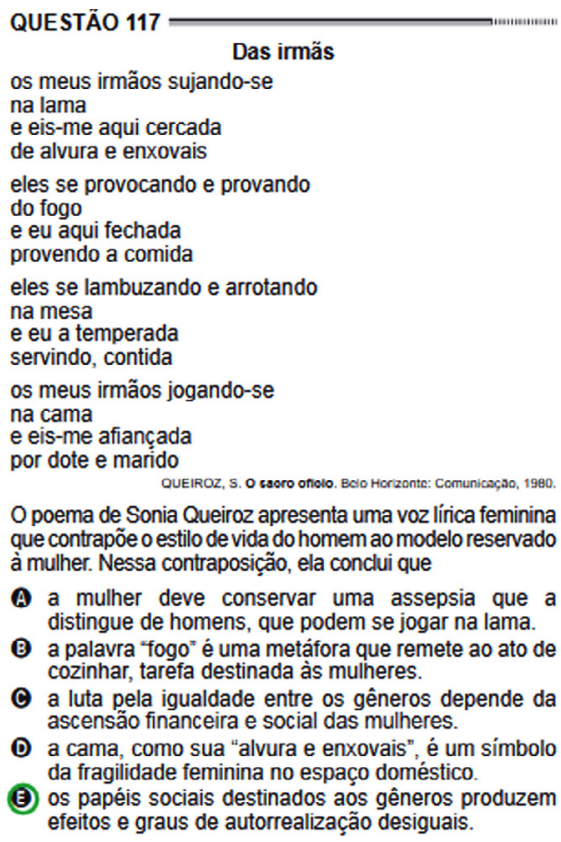

O poema de Sonia Queiroz apresenta uma voz lírica feminina que contrapõe o estilo de vida do homem ao modelo reservado à mulher. Nessa contraposição, ela conclui que

A a mulher deve conservar uma assepsia que a distingue de homens, que podem se jogar na lama.

B a palavra "fogo" é uma metáfora que remete ao ato de cozinhar, tarefa destinada às mulheres.

C a luta pela igualdade entre os gêneros depende da ascensão financeira e social das mulheres.

D a cama, como sua "alvura e enxovais", é um símbolo da fragilidade feminina no espaço doméstico.

(E) os papéis sociais destinados aos gêneros produzem efeitos e graus de autorrealização desiguais.

Figuras o3 e 04: Questões do Caderno 7 do ENEM 2012 - Prova Azul. Fonte: INEP - Provas e Gabaritos 
$\mathrm{Na}$ questão 100, temos um texto literário que, mesmo organizado em prosa, traz recursos poéticos que conferem plurissignificância ao texto. Apesar disso, a formulação da questão acabou por reduzir a multiplicidade de sentidos possíveis, na medida em que foi salientado o aspecto corporal, evidente na construção textual, mas nem por isso o mais importante. $\mathrm{O}$ autor do texto vai além das questões físicas, fincando sua problemática no mistério que é o ser. Poder-se-ia no caso chamar atenção para a linguagem poética do texto, explorando mais seus recursos especificamente literários.

Além disso, podemos notar uma certa superficialidade das alternativas, sendo as erradas facilmente descartáveis. Ou seja, contrariando a própria fundamentação do exame, a questão não se configura como uma situação-problema adequada, pois não coloca obstáculo a ser ultrapassado e que convide à reflexão, assim como não expressa diferentes graus de articulação entre o enunciado e a alternativa que melhor define a resolução do problema.

Já a questão 117 traz um poema de Sonia Queiroz, intitulado "Das irmãs". Através dele, tenta-se abordar aspectos referentes ao estilo de vida reservado tradicionalmente à mulher e ao homem na sociedade. Se comparada à questão 100, notamos que a 117, através de algumas alternativas (como A, B e D), destaca características da linguagem poética, como a metáfora e a simbologia, o que, a princípio, faria o candidato voltar ao texto para construir sentidos com base na exploração desses recursos, mas, na verdade, houve uma redução semântica pela forma como a alternativa correta se apresenta; a interpretação solicitada na questão poderia ser operada a partir de um texto qualquer (jornalístico, por exemplo). Pelo que se pode notar, mesmo se valorizando a leitura do texto, deixa-se de lado o trabalho com as especificidades da linguagem literária.

No que tange à prova da UFPE, ela apresenta 16 questões, nas quais são explorados assuntos catalogados no Manual do Candidato (UFPE, 2012). Trata-se de uma listagem de movimentos literários, autores e leituras recomendadas. No caso do vestibular 2012-2013, o conteúdo programático de literatura era o seguinte: 

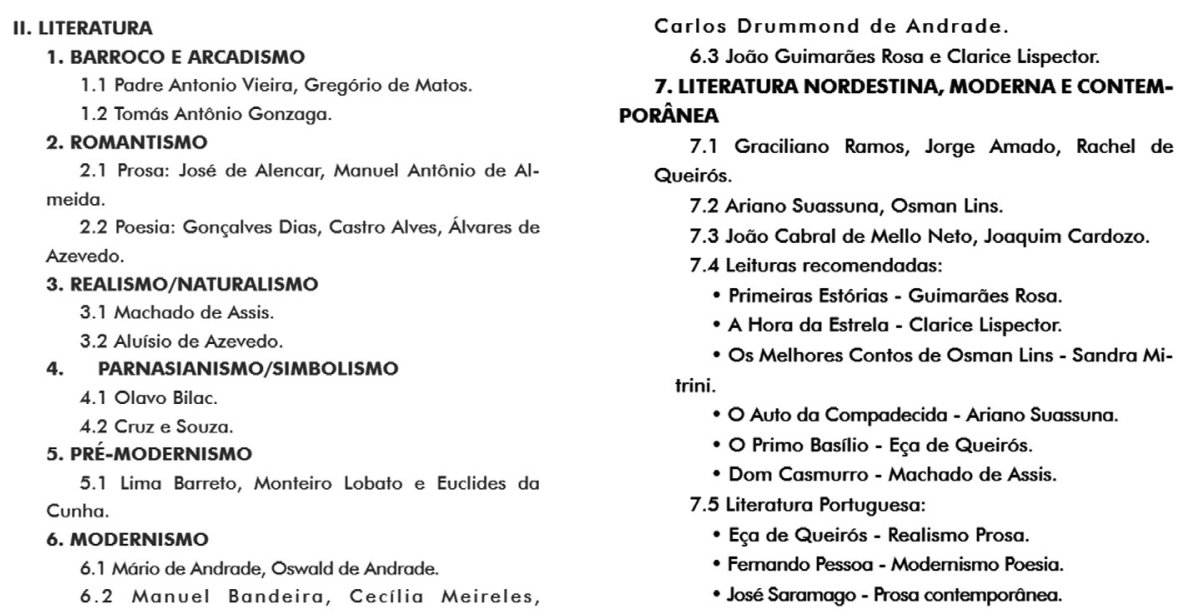

Figuras o5 e 06: Conteúdo programático de literatura

Fonte: Manual do Candidato - Vestibular UFPE 2012-2013

Visto esse caráter meramente conteudista da prova, já perceptível no manual, ao analisarmos as questões, constatamos que a grande maioria prioriza a memorização em algumas de suas alternativas. Mesmo havendo a predominância de questões que tragam algum texto literário para ser explorado, recorre-se a alguma informação sobre o autor, o momento histórico ou o discurso da crítica literária. Examine-se o exemplo abaixo: 
01. A comunicação literária implica a interação entre o escritor e seu público num contexto histórico determinado. Dessa forma, os elementos contextuais e históricos interferem na produção estética da literatura. Tendo em vista esse princípio, analise a relação que os enunciados abaixo estabelecem entre momentos da História brasileira e a literatura nacional.

$0-0$ ) Os primeiros vinte anos do século $X X$ no Brasil foram marcados pela implantação do regime republicano. O clima de euforia e de progresso foi filtrado por romancistas talentosos, como Lima Barreto e Monteiro Lobato, os quais, numa linguagem mais realista, representavam um povo confiante de si.

1-1) O crescimento da maquinaria modema no Brasil, somado ao contato que os intelectuais burgueses mantinham com a modernidade europeia, contribuiu para que poetas como Mário de Andrade e Oswald de Andrade buscassem uma expressão poética condizente com a velocidade da vida moderna.

2-2) A Ditadura de Vargas fez surgir uma literatura nacionalista e tradicionalista, que reforçava o ponto de visța assumido pelo poder político hegemônico. É o caso do romance regionalista, que teve por representantes, entre outros, Graciliano Ramos e Jorge Amado.

3-3) Após as consequências desastrosas da segunda Guerra Mundial, instaurou-se no imaginário ocidental uma dúvida quanto às verdades da ciência. A abertura do homem para a dimensão mística da realidade se refletiu, no Brasil, na produção literária de um Guimarães Rosa, por exemplo.

4-4) As grandes transformações operadas no Ocidente pelo Capitalismo, em sua terceira fase, abriram os mercados nacionais para os trânsitos migratórios. O consumo desenfreado $e$ a publicidade de produtos postos à venda contribuíram para a produção estética de uma poesia visual, como a concreta ou semiótica.

Figura 07: Questão da prova de literatura - Fonte: Provas e Gabaritos UFPE 2013. Disponível em: $<$ http://vestibular.brasilescola.uol.com.br/downloads/universidade-federal-pernambuco.htm>

Nessa questão, podemos ver claramente as consequências de uma avaliação que prioriza conteúdos em si mesmos: do candidato é cobrado que ele já tenha um conhecimento prévio (neste caso, sobre história do Brasil e da literatura) para 
responder a questão. Geralmente, questões desse tipo são marcadas por "pegadinhas”, característica que é rechaçada nos documentos que orientam a formulação da prova do ENEM, como já dito. Em outras questões que trazem textos literários, ressaltam-se aspectos superficiais, como algum episódio específico do enredo da obra ou a reprodução de algum discurso cristalizado pela crítica literária.

No entanto, por tudo o que foi visto sobre as duas provas, consideramos que, por tentar avaliar competências e habilidades, tendo a atividade leitora como competência principal, a prova do ENEM mostra-se mais significativa em termos do trabalho com o texto literário, em comparação com a da UFPE. Vale lembrar que "estudar literatura é mais que estudar a sua historiografia, sendo esta, sem dúvida, uma preocupação patente nas abordagens previstas pela matriz de referência” (MEDEIROS, 2011, n. p.).

Isso se reflete na concepção geral de cada um dos exames: enquanto o ENEM “aponta para uma interação maior entre disciplinas afins" (BARRETTO, 2000, p. 94), ressaltando os princípios da interdisciplinaridade e da contextualização, a UFPE trata as disciplinas de forma isolada e valoriza mais informações e conteúdos do que a reflexão sobre eles.

\section{CRITÉRIO 3 - CONSONÂNCIA DAS PROVAS COM O PRINCÍPIO DA FORMAÇÃO DE LEITORES DO TEXTO LITERÁRIO}

Neste ponto, é importante destacar a orientação de Cosson (2009) acerca do letramento literário. Para ele, "a orientação fundamental é que o letramento literário precisa acompanhar, por um lado, as três etapas do processo de leitura, e por outro, o saber literário" (COSSON, 2009, p. 47). Essas três etapas são: a) antecipação, em que serão levados em conta tanto os objetivos da leitura e sua materialidade; b) decifração, quando o indivíduo começa a se familiarizar com o texto para que haja a c) interpretação, que se dá quando o leitor dialoga com "o texto tendo como limite o contexto." (ibid., p. 41).

No que respeita ao saber literário, o mesmo autor afirma:

[...] a literatura é uma linguagem que compreende três tipos de aprendizagem: a aprendizagem da literatura, que consiste fundamentalmente em experienciar o mundo por meio da palavra; a aprendizagem sobre a literatura, que envolve conhecimentos de história, teoria e crítica; e a aprendizagem por meio da literatura, nesse caso os saberes e as habilidades que a prática da literatura proporciona aos seus usuários. (ibid., p. 47). 
Partindo desses pressupostos, ao analisarmos as provas do ENEM e da UFPE, notamos que pelo menos um desses três tipos de aprendizagem a respeito da literatura está sempre presente. No caso do ENEM, notamos a predominância da aprendizagem por meio da literatura, visto que o exame está baseado na interdisciplinaridade e no agrupamento dos conteúdos em grandes áreas de conhecimento. Já na UFPE, predomina a aprendizagem sobre a literatura, que, sozinha, não é capaz de formar um leitor proficiente de textos literários. Além das questões apresentadas nas figuras 4 e 7 (a primeira, do ENEM, exemplifica a aprendizagem por meio da literatura; a segunda, da UFPE, exemplifica a aprendizagem sobre a literatura), podemos destacar também as amostras a seguir: 


\section{QUESTÃO 105 \\ O senhor}

Carta a uma jovem que, estando em uma roda em que dava aos presentes o tratamento de você, se dirigiu ao autor chamando-0 "o senhor":

Senhora:

Aquele a quem chamastes senhor aqui está, de peito magoado e cara triste, para vos dizer que senhor ele não é, de nada, nem de ninguém.

Bem o sabeis, por certo, que a única nobreza do plebeu está em não querer esconder sua condição, e esta nobreza tenho eu. Assim, se entre tantos senhores ricos e nobres a quem chamáveis você escolhestes a mim para tratar de senhor, é bem de ver que só poderieis ter encontrado essa senhoria nas rugas de minha testa e na prata de meus cabelos. Senhor de muitos anos, eis ai; o ternitório onde eu mando é no país do tempo que foi. Essa palavra "senhor", no meio de uma frase, ergueu entre nós um muro frio e triste.

Vi o muro e calei: não è de muito, eu juro, que me acontece essa tristeza; mas também não era a vez primeira.

BRAGA, R. A borbolote amorola. Ria de Jonsire: Rocerd, 1991.

A escolna do tratamento que se queira atribuir a alguém geralmente considera as situações especificas de uso social. A violação desse principió causou um mal-estar no autor da carta. O trecho que descreve essa violação é:

(2) "Essa palavra, 'senhor', no meio de uma frase ergueu entre nós um muro frio e triste."

B "A única nobreza do plebeu está em não querer esconder a sua condição."

C "Só poderieis ter encontrado essa senhoria nas rugas de minha testa."

(1) "O território onde eu mando é no país do tempo que foi."

€ "Não é de muito, eu juro, que acontece essa tristeza; mas também não era a vez primeira."
07. A poesia lírica é o espaco ideal para a temática do amor, desde a antiguidade dássica até a atualidade. Mudam-se os tempos, as ideologias, e 0 amor continua um sentimento indecifrável e paradoxal. Dai ser motivo dos dois poemas que seguem. Leia-os e analise as proposiçỏes que a eles se referem.

Sete anos de pastor Jacó servia

Sete anos de pastor Jacó servia

Labäo, pai de Raquel, serrana bela

Mas nấo servia ao pai, servia a ela.

E a ela só por prêmio pretendia.

Os dias, na esperanca de um só dia,

Passavava. contentando-se com vê-la:

Porem o pai, usando de cautela,

Em lugar de Raquel the dava Lia.

Vendo o triste pastor que com enganos

Lhe fora assim negada a sua pastora.

Como se náo a tivera merecida,

Começa de servir outros sete anos.

Dizendo: - Mais servira se näo fora

Para tão longo amor tăo curta a vida

Soneto de Fidelidade

De tudo, ao meu amor serei atento

Antes, e com tal zelo, e sempre, e tanto

Que mesmo em face do maior encanto

Dele se encante mais meu pensamento.

Quero vivê-lo em cada vão momento

E em seu louvor hei de espalhar meu canto

E rir meu riso e derramar meu pranto

Ao seu pesar ou seu contentamento.

E assim, quando mais tarde me procure

Quem sabe a morte, angústia de quem vive

Quem sabe a solidäo, fim de quem ama

Eu possa me dizer do amor (que tive):

Que năo seja imortal, posto que é chama

Mas que seja infinito enquanto dure.

(Viniclus de Moraes)

0-0) Nos dois poemas, pertencentes. respectivamente. ao Classicismo e ao Romantismo, o tema do amor é trabalhado numa forma fixa.

1-1) Săo dois sonetos que mantêm relaçâo de intertextualidade, pois o segundo retoma o primeiro em sua forma e em seu conteúdo.

2-2) Nos dois poemas, a concepçäo de amor $\dot{e}$ diversa, pois o primeiro expressa a finitude desse centivanto apresenta-o como etemo.

3-3) No último verso de seu poema. Camões usa uma antitese para dar conta da idealizaçäo do amor. Vinicius de Moraes, nos dois ưltimos versos do segundo quarteto, recorre tambèm a oposicóes, que expressam o desejo de viver 0 sentimento amoroso em todos os momentos.

4-4) Enquanto o segundo soneto apresenta uma concepçäo do amor mais fel à vivência dos afetos no século $X X$. o primeiro traz uma visäo platônica idealizada do sentimento amoroso. própria do Classicismo do século XVI.

Figuras 08 e 09: Questão do caderno 7 do ENEM - prova azul. Fonte: INEP - Provas e Gabaritos; Questão da prova de literatura da UFPE 2013. Fonte: Provas e Gabaritos UFPE 2013 
Na questão 105, notamos que através do texto literário se tenta contemplar aspectos referentes à comunicação social (no caso, o uso das formas de tratamento). Contudo, a questão do trato cerimonioso expresso pelo termo "Senhor" se sobrepôs ao texto como um todo, que, novamente, deixou de ser explorado em sua especificidade e plurissignificância (ironia, metáfora, sentimentos do eu lírico, distância entre gerações, velhice x juventude, relações de poder, intergenericidade textual etc.).

$\mathrm{Na}$ questão 07, mesmo havendo uma proposta interessante de intertextualidade entre textos de épocas distintas (séculos XVI e XX), notamos que se requer, através da alternativa o-o, por exemplo, a memorização de informações: o candidato precisaria saber previamente a que escola literária cada texto pertenceu.

Um exemplo de questão do ENEM em que pudemos observar um trabalho mais significativo com a leitura literária é a de número 126 (já mostrada aqui). Nela, é possível perceber que toda a problematização parte do texto literário e se tomam como recursos para a interpretação as especificidades do próprio texto literário (sua construção através da metáfora, da alegoria e da simbologia). Além disso, a questão também contextualiza o texto num tempo e num espaço, sem perder de vista sua especificidade literária.

Visto que o ENEM, diferentemente da UFPE, traz questões desse tipo, além de outras que avaliam a aprendizagem por meio da literatura, podemos concluir que esse exame se aproxima mais do que esperamos no sentido de uma abordagem mais significativa do texto literário, se comparado a exames tradicionais, em que a aprendizagem sobre a literatura é preponderante.

Como o ENEM valoriza, principalmente, o pensar/refletir, com vistas ao "saber fazer", através de competências e habilidades, pode-se dizer que uma marca importante da prova é o desenvolvimento das competências tidas como gerais e transversais, embora isso implique, frequentemente, que não sejam ressaltadas as propriedades específicas de qualquer das linguagens empregadas nas questões. Assim, também no caso do ENEM, não se preza pela formação de um leitor proficiente do texto literário, para o que seria necessário um maior investimento na aprendizagem $d a$ literatura, tendo em vista suas características peculiares, apontadas por Paulino (2005). A necessidade de olhar para aquilo que é propriamente literário também foi destacada por Bordini e Aguiar (1993, p. 14):

A literatura, como umas das formas de comunicação, participa assim, do âmbito maior da cultura, ou seja, de produção significante, relacionando-se com outros objetos 
culturais. Entretanto, possui características que a diferenciam desses. A mais evidente é o uso não utilitário da linguagem.

Pensar tudo isso é importante, pois essas provas, muitas vezes, norteiam as aulas de literatura e, segundo Cosson (2009, p. 47), "as práticas de sala de aula precisam contemplar o processo de letramento literário e não apenas a mera leitura das obras”.

\section{Conclusões}

Concluímos que a prova do ENEM 2012 cumpre com o que é proposto em sua fundamentação e matriz de referência no que diz respeito ao desenvolvimento de competências e habilidades, com ênfase no desenvolvimento das competências transversais. Essa característica, de certa forma, compromete o trabalho com a linguagem literária; esta apresenta especificidades que muitas vezes são deixadas de lado, pois, como a competência de leitura e interpretação é tratada de maneira uniforme para qualquer gênero textual, o texto literário se torna um texto informativo, do qual se solicita uma leitura quase que literal. Já o vestibular da UFPE, que poderia voltar mais a atenção para o texto literário e suas especificidades, posto que nele há uma prova exclusiva para a literatura e muitas de suas questões apresentam textos literários, termina por avaliar mais a aprendizagem sobre a literatura (vida do autor, história da literatura, discurso da crítica). Pode-se afirmar que, mesmo o ENEM mostrando-se precário no tratamento com o texto literário, esse exame representa um avanço, se comparado a exames tradicionais, pois, através de suas situações-problema, exige-se mais reflexão acerca do texto. Por fim, é importante reafirmar que o modo como o texto literário é abordado nos exames influencia o modo como ele será abordado na escola. Por isso, é necessário que os formuladores empreendam um trabalho mais significativo em relação a esse tipo de texto.

\section{REFERÊNCIAS}

ABAURRE, M. B. M. Vestibular discursivo da UNICAMP: um espaço de interação entre a Universidade e a Escola. Ensaio: Avaliação de políticas públicas em educação. Rio de Janeiro, v. 3, n. 9, p. 481-485, out./dez., 1995 .

BARRETTO, E. S. S. A propósito das Orientações Curriculares Nacionais para o Ensino Médio. Estudos em Avaliação Educacional. São Paulo, Fundação Carlos Chagas, n. 22, p. 93-99, jul.-dez., 2000. 
BORDINI, M. G.; AGUIAR, V. T. Literatura: a formação do leitor - alternativas metodológicas. Porto Alegre: Mercado Aberto, 1993.

BRASIL. Ministério da Educação. Lei no 9.394, de 20 de dezembro de 1996. Estabelece as diretrizes e bases da educação nacional. Disponível em: <http://www.planalto.gov.br/ccivil_03/Leis/ L9394.htm>. Acesso em: 12 jun. 2016.

BRASIL. Ministério da Educação. Exame Nacional do Ensino Médio - Documento básico. Brasília: INEP, 2002.

BRASIL. Ministério da Educação. Instituto Nacional de Estudos e Pesquisas Educacionais Anísio Teixeira. Exame Nacional do Ensino Médio (ENEM): fundamentação teórico-metodológica. Brasília: INEP, 2005.

BRASIL. Ministério da Educação. Conselho Nacional de Educação. Câmara de Educação Básica. Resolução no 2, de 30 de janeiro de 2012. Define Diretrizes Curriculares Nacionais para o Ensino Médio. Brasília: CNE/CEB, 2012a.

BRASIL. Ministério da Educação. Instituto Nacional de Estudos e Pesquisas Educacionais Anísio Teixeira. Edital n ${ }^{\circ}$ 3, de 24 de maio de 2012. Exame Nacional do Ensino Médio - ENEM 2012. Brasília: INEP, 2012b. Disponível em: <http://download.inep.gov.br/educacao_basica/enem/ edital/2012/edital-enem-2012.pdf >. Acesso em: 12 jun. 2016.

CORTELAZZO, A. L. Utilização do ENEM pelas universidades estaduais paulistas: abordagem quantitativa da abrangência do exame e desempenho dos egressos de escolas públicas e privadas de ensino médio. Ensaio: Avaliação de políticas públicas em educação. Rio de Janeiro, v. 11, n. 39, p. 210-221, abr./jun. 2003.

COSSON, R. Letramento Literário: teoria e prática. São Paulo: Contexto, 2009.

CURY, C. R. J. O ensino médio no Brasil: histórico e perspectivas. Educação em revista, Belo Horizonte, n. 27, p. 73-98, jul., 1998.

KRAWCZYK, N. A escola média: um espaço sem consenso. Cadernos de pesquisa, São Paulo, n. 120, p. 169-202, nov. 2003.

LOPES, A. C.; LÓPEZ, S. B. A performatividade nas políticas de currículo: o caso do ENEM. Educação em revista. Belo Horizonte, v. 26, n. o1, p. 89-110, abr. 2010.

MARCELINO, L. V. e RECENA, M. C. P. Possíveis influências do novo ENEM nos currículos educacionais de Química. Estudos em Avaliação Educacional. São Paulo, v. 23, n. 53, p. 148-177, set./dez., 2012.

MEDEIROS, L. R. C. A que serve a literatura no ENEM? In: ENCONTRO NACIONAL DE LITERATURA INFANTO-JUVENIL E ENSINO - ENLIJE, 4., 2011, Campina Grande. Anais... Campina Grande: UFCG. 2011. Não paginado. Disponível em: <http://www.editorarealize.com. br/revistas/enlije/anais.php>. Acesso em: 01 ago. 2014.

MILDNER, T., SILVA, A. O ENEM como forma alternativa ou complementar aos concursos vestibulares no caso das áreas de conhecimento "Língua Portuguesa e Literatura": relevante ou passível de refutação? Estudos em avaliação educacional, n. 25, p. 43-75, jan.-jun., 2002.

PAULINO, G. Algumas especificidades do texto literário. In: REUNIÃO ANUAL DA ANPED, 28, 2005, Caxambu, MG. Anais... Caxambu, MG: ANPED, 2005. 
PEREIRA, L. C.; SOUZA, N. A. Concepção e prática de avaliação: um confronto necessário no ensino médio. Estudos em avaliação educacional, n. 29, p. 191-208, jan.-jun., 2004.

PINTO, F. C. P.; LETICHEVSKY, A. C.; GOMES, S. C. O ENEM em síntese: propostas teóricas e desdobramentos. Ensaio: Avaliação de políticas públicas em educação. Rio de Janeiro, v. 11, n. 40, p. 261-282, jul./set., 2003.

RAMOS, F. B.; ZANOLLA, T. Repensando o ensino de literatura no Ensino Médio: a interação texto-leitor como centro. Contrapontos, Itajaí. vol. 9, n. 1, p. 65-80, jan./abr., 2009.

SANTOS, J. M. C. T. Exame Nacional do Ensino Médio: entre a regulação da qualidade do Ensino Médio e o vestibular. Educar em revista, Curitiba, Brasil, n. 40, p. 195-205, abr./jun., 2011.

SOARES, M. Ler, verbo transitivo. In: PAIVA, A. et al. (Org.). Leituras literárias: discursos transitivos. Belo Horizonte: Ceale; Autêntica, 2014. p. 29-34.

SOUSA, S. M. Z. L. Possíveis impactos das políticas de avaliação no currículo escolar. Cadernos de Pesquisa, n. 119, p. 175-190, julho/2003.

UNIVERSIDADE FEDERAL DE PERNAMBUCO. Comissão de Processos Seletivos e Treinamentos. Manual do candidato do vestibular UFPE 2012-2013. Recife: UFPE, 2012.

ZANCHET, B. M. B. O Exame Nacional do Ensino Médio - ENEM: uma autoavaliação para quem? Avaliação - Revista da Rede de Avaliação Institucional da Educação Superior, v. 8, n. 1, p. 247-268, mar., 2003.

\section{SOBRE OS AUTORES}

Lívia Suassuna é licenciada em Letras-Português (Universidade Federal de Pernambuco), Mestre em Língua Portuguesa (Pontifícia Universidade Católica de São Paulo) e Doutora em Linguística (Universidade Estadual de Campinas). É Professora Associada da Universidade Federal de Pernambuco (Centro de Educação - Departamento de Métodos e Técnicas de Ensino e Programa de Pósgraduação em Educação). Tem experiência na área de Linguística, com ênfase em Metodologia do Ensino de Língua Portuguesa.

E-mail: livia.suassuna@ufpe.br

Rafael Alexandre Bezerra é graduado em licenciatura em Letras-Português (Universidade Federal de Pernambuco) e foi bolsista do Programa Institucional de Bolsas de Iniciação Científica (PIBIC) no período de 2013 a 2015. E-mail: rafaelalexandre1204@gmail.com

Recebido em 22 de março de 2016 e aprovado em 25 de agosto de 2016. 